\title{
A Tale of Two Cities: From Influenza HxNy to SARS-CoV-z
}

\author{
William J. Liu ${ }^{1, *}$; Shelan $\mathrm{Liu}^{2,3, *}$
}

\section{THE COMMON FEATURES OF VIRUSES WITH PANDEMIC POTENTIAL}

In the past hundred years, human population expansion and globalization have changed the pattern of human-nature interactions and accelerated the emergence and spread of novel infectious diseases (1). Humans have experienced a long list of microbial threats to health, of which, $70 \%$ are believed to be from animal reservoirs (2), such as severe acute respiratory syndrome coronavirus (SARS-CoV), Middle East respiratory syndrome coronavirus (MERS$\mathrm{CoV})$, and avian influenza A (H7N9) viruses, etc., emerging in 2002-2003, 2012, and 2013, respectively (3). Among the microbial threats, pandemic-causing viruses have profound and far-reaching impacts on public health, the economy, and society. Pandemics in the past century were mainly caused by influenza viruses: $1918 \mathrm{H} 1 \mathrm{~N} 1,1957 \mathrm{H} 2 \mathrm{~N} 2,1968 \mathrm{H} 3 \mathrm{~N} 2$, and 2009 H1N1, defined by World Health Organization (WHO), together with the re-emergence of $\mathrm{H} 1 \mathrm{~N} 1$ influenza virus in 1977 (4-5). At the end of 2019, coronavirus disease 2019 (COVID-19) with human coronavirus-19 (hCoV-19, also termed SARS-CoV-2 by International Committee on Taxonomy of Viruses) as the causative agent, emerged and became the largest and most devastating pandemic in the new century (G). Currently, the world is still in the midst of this coronavirus pandemic. As two pandemic-risk viruses both transmitting through respiratory tracts, it raises concerns on how SARS-CoV-2 and influenza viruses themselves, and the relevant public health measures and scientific researches influence each other.

SARS-CoV-2 and influenza viruses have many common characteristics which may correlate with the driving force of pandemics. The respiratory tract as the transmission route enables the disease to spread globally in a short time. The considerable number of latent or asymptomatic infections and mild cases brings difficulty to the control of the diseases ( 7 ). Emerging viral variants present alarming characteristics, including increased transmissibility and infectivity, alternative drug resistance, and immune escape. The wide range of animal hosts for the influenza viruses and the recentlydiscovered diverse susceptible animals of SARS-CoV-2 provides potentials for reemergence, though the animal reservoir of SARS-CoV-2 has not been confirmed (8). Thus, these common features of the two viruses imply that knowledge can be shared in the control of them.

\section{THE PREPARENESS FOR FLU PANDEMIC BENEFITS THE COVID-19 RESPONSES}

Looking back on the hundred-year history of humans fighting against influenza, most experience of responding to the pandemic comes from this process. At the very beginning of the COVID-19 pandemics, plenty of experts on influenza took on the mission and applied the experience derived from prevention, control, and research on influenza to COVID-19. The Chinese National Influenza Center undertook most of the hCoV-19 (previous name of SARS-CoV-2) genome sequencing work in the National Institute for Viral Disease Control and Prevention of China CDC (9). Since its launch, the Global Initiative on Sharing All Influenza Data (GISAID) played an essential role in the sharing of data from influenza viruses. After initial deposition of the $\mathrm{hCoV}-19$ whole genome sequences by China CDC, authorities and researchers looked to GISAID for its expertise in facilitating rapid sharing of trusted data (9). Currently, more than five million hCoV-19 genome sequences have been shared on GISAID since January 2020 and are helping the scientists study the new virus (10), together with other SARS-CoV-2 databases, such as RCoV19 from the China National Center for Bioinformation (11). Thus, the accumulated experiences, techniques, and human resources from influenza pandemic preparation have played an important role in the responses to COVID-19 pandemic (12). Interestingly, the in-depth and extensive researches on COVID-19 by a large number of scientists gathered in a short period of time have also promoted our understanding of influenza viruses and improved the prevention and response capacity. New vaccines and drugs, such as mRNA 
vaccine and monoclonal antibody drugs, are quickly being developed and used with emergency authorizations (13). Nucleic acid testing is becoming widely accepted (14), and traceability of the new virus has received unprecedented attention not only from the scientific community (15). The evidence of the introduction and spread of SARS-CoV-2 through cold chain also brings into reconsideration of the seasonal features of influenza viruses (16).

\section{THE SITUATIONS AND REASONS OF IMPACT OF COVID-19 ON THE FLU EPIDEMIC}

Since the emerging of COVID-19, influenza activity in different countries plunged in early 2020 and stayed at lower levels than expected during the 2020-2021 season (17-18). In China, influenza-like illness (ILI) activity across the country was significantly lower in 2020 compared to 2015-2019 (Figure 1). Furthermore, the influenza positive rate in 2021 has remained below the national epidemic threshold $(15.5 \%)$ as of Week 43, although the overall weekly ILI rate and influenza positive rate since Week 13 of 2021 was slightly higher than the rate during the same period in 2020 (Figure 1). Public health interventions against COVID-19 decreased influenza activity directly. With similar routes of transmission, the mitigation methods used to prevent COVID-19 transmission also reduced influenza transmission (19). Hygiene habits of the public, including mask wearing, hand washing, and proper ventilation, have been broadly advocated. Other non-pharmaceutical interventions (NPIs) for COVID-19 also restricted the transmission of influenza, e.g., canceling of mass gatherings, closing public entertainment venues and schools, restricting domestic and international travel, issuing stay-at-home orders, and active and passive quarantine of cases with febrile respiratory syndrome. However, the reported SARS-CoV-2 and influenza virus co-infections indicated that SARS-CoV-2 itself does not repel the influenza virus in the host and no cross-immunity between the two viruses exits (20-21).

\section{THE CHALLENGES OF CO- CIRCULATION OF FLU AND COVID-19 IN THE SECOND HALF}

During the second half of the war against COVID-19, the influenza activities will become complicated and difficult to predict. Key challenges are posed to the prevention and control of the two viruses (22). First, some countries no longer consider COVID-19 a social critical disease and have lifted their social restrictions. The NPIs will be relaxed incrementally, which is expected to result in higher influenza infection over the following flu season. Second, the low circulation of the influenza virus in recent seasons challenges the prediction of potential prevalent influenza viruses from the currently limited genetic variants, which increases the likelihood of influenza vaccine mismatch. Third, similar to the emerging of the new variants of SARS-CoV-2 with higher transmission capacity and changed antigenicity, the new genetic variants of influenza viruses may also erupt under a selective pressure of current NPIs against COVID-19. Fourth, global population immunity to influenza will have decreased with very low levels of influenza activity in the recent seasons. Fifth, the shifting of medical personnel and resources in favour of COVID-19 in some countries and regions will continuously impact the capacity of health services to respond to a potential influenza pandemic (23). Furthermore, a potential co-circulation of other respiratory viruses, including respiratory syncytial virus, will make the situation more complicated in the future seasons (24).

\section{PERSPECTIVES AND SUGGESTIONS}

Facing the complicated situation of co-circulation of SARS-CoV-2 and influenza viruses together with other respiratory pathogens, comprehensive prevention and control strategies are needed. First, it is important to enhance the WHO's Global Influenza Surveillance and Response System to monitor the respiratory viruses (25). Effective continuous surveillance of any new variants is key for providing early warnings. The epidemic model based on the new circumstances remolded by the diseases will provide new insights into the regularity and give useful references for the strategies. Second, active NPIs are still an economic tool to control the spread and to decrease the impact of an influenza endemic. The relaxation of NPIs with the increasing coverage of SARS-CoV-2 vaccination in some countries should be gradually stepped up and fully assessed for risks. Third, rapid differential diagnosis of COVID-19, influenza, and other respiratory pathogens is needed, especially during the winter. It is a good choice to develop rapid dual or multiplex diagnostic tests to distinguish between these two viruses and other respiratory pathogens, 

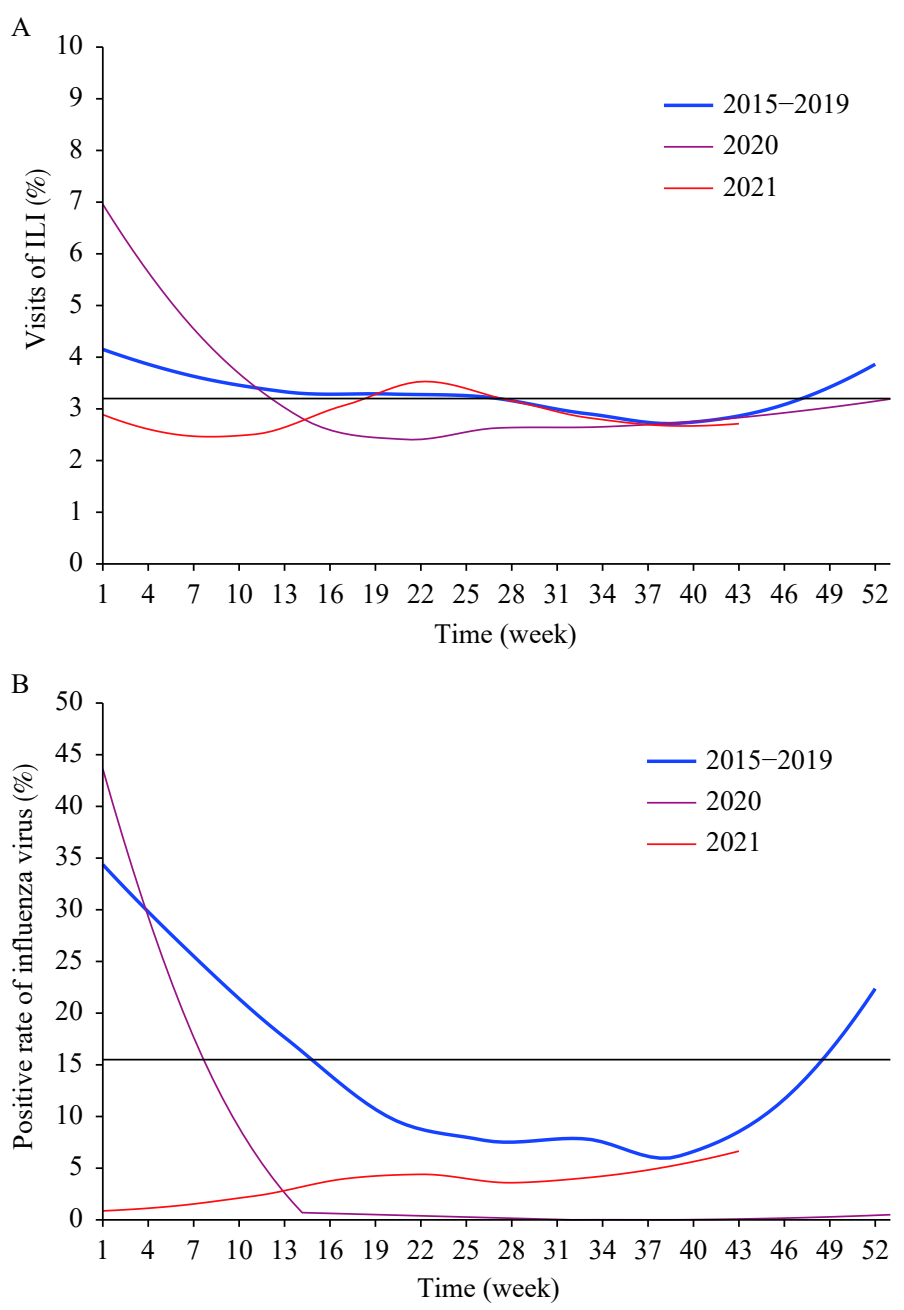

FIGURE 1. Percentage of visits for (A) influenza like illness and (B) influenza virus positivity at sentinel hospitals in overall China, during 2020 and 2021 compared with 2015 to 2019.

Notes: Average weekly percentage of visits for ILI was 3.0\% in 2020 compared with the average ILI 3.2\% of 2015-2019, with a drop of $6.25 \%(P<0.001)$; the percentage was further decreased by $10 \%$ from the ILI $3.0 \%$ in 2020 to ILI $2.7 \%$ in 2021 $(P<0.001)$. Average weekly positive influenza virus rate decreased by $61.94 \%(P<0.001)$ from $2015-2019(15.5 \%)$ to 2020 $(5.9 \%)$, and continuously decreased by $44.07 \%(P<0.001)$, from $2020(5.9 \%)$ to $2021(3.3 \%) .1)$ All data were collected from Chinese National Influenza Center Weekly Report (http://www.chinaivdc.cn/cnic/zyzx/lgzb/202111/t20211105_252585.htm). 2) R software (R4.0.4 version, R Development Core Team, Auckland, New Zealand) was used to analyze the data and generate the figures. 3) Two proportional tests were used to check the differences in average weekly ILI percentage and influenza virus positivity over the years from 2015 to 2021. 4) Black lines in Panel A and B denoted the national epidemic thresholds during 2015-2019, i.e. 3.26 ILI cases per 100 outpatient visits and the influenza positive rate (15.5\%), respectively. 5) The blue line in Panel A indicates the calculated mean values of ILI in each week during 2015-2019. The mean values of ILI= the sum of ILI among 2015-2019/the total visits for ILI at sentinel hospitals among 2015-2019 in overall China by week; 6) The blue line in Figure B indicates the calculated mean influenza virus positivity in each week among 2015-2019. The mean influenza virus positivity = the sum of influenza virus positive samples among 2015-2019/the total samples collected for ILI at sentinel hospitals among 2015-2019 in China overall by week.

Abbreviation: ILI=influenza-like illness.

particularly among front-line healthcare professionals and other populations with high risks for exposure. Early diagnosis will facilitate isolation, management, and treatment of both hospitalized patients and outpatients. Fourth, the average national vaccination coverage for influenza varies greatly across countries.
Thus, at the same time as popularizing the COVID-19 vaccines and even its booster, influenza vaccination coverage should also be encouraged. The immunological barrier at the population-level established through vaccination is always a safe and economic pathway to interrupt transmission (26). The 
theme of World Flu Day this year (the 4th) is "Flu and COVID-19: Let's get vaccinated" (27-28). Lastly, scientific investigations on these pandemic-risk viruses should also be enhanced. For instance, we should assess the risks of already emergent influenza viruses, such as human-infecting avian influenza A (H5N6) viruses including the transmission, infection, immunogenicity and drug resistance, etc. (29). The development of universal vaccines, drugs, and testing reagents will be prepared for future pandemics induced by the viruses from the same family or at least the same genera.

The emergence and re-emergence of diverse subtypes of influenza A viruses, which are known as "HxNy" mediated through the reassortment of viral genomes, together with influenza B viruses will continuously account for future pandemics. Beyond SARS-CoV and current SARS-CoV-2, we are not sure whether there will be a "SARS-CoV-z" in the future. However, with experiences from the responses to influenza and SARS-CoV-2, a series of prevention and mitigation measures, including new diagnosis and surveillance technologies, pharmaceutical measures and NPIs are developed to help preserve and boost the capacity and function of health systems across the world. We can do these better for the next virus!

Conflicts of interest: No conflicts of interest.

Funding: Supported by Zhejiang Provincial Program for the Cultivation of High-level Innovative Health talents, the Medical and Health Research Project of Zhejiang Health Commission (No. 2020KY525), Zhejiang Provincial Natural Science Foundation of China under (No. GF21H260012), and the Excellent Young Scientist Program of the National Natural Science Foundation of China (No. 81822040).

\section{doi: $10.46234 / \mathrm{ccdcw} 2021.256$ \\ \# Corresponding authors: William J. Liu, liujun@ivdc.chinacdc.cn;} Shelan Liu, liushelan@126.com.

${ }^{1}$ Chinese National Influenza Center (CNIC), National Institute for Viral Disease Control and Prevention, Chinese Center for Disease Control and Prevention, Beijing, China; ${ }^{2}$ Department of Infectious Diseases, Zhejiang Provincial Center for Disease Control and Prevention, Hangzhou, Zhejiang, China; ${ }^{3}$ Key Laboratory of Vaccine, Prevention and Control of Infectious Disease of Zhejiang Province, Hangzhou, Zhejiang, China.

Submitted: October 20, 2021; Accepted: November 30, 2021

\section{REFERENCES}

1. Morens DM, Fauci AS. Emerging pandemic diseases: how we got to COVID-19. Cell 2020;183(3):837. http://dx.doi.org/10.1016/j.cell. 2020.10.022.

2. Jones KE, Patel NG, Levy MA, Storeygard A, Balk D, Gittleman JL, et al. Global trends in emerging infectious diseases. Nature 2008;451(7181):990 - 3. http://dx.doi.org/10.1038/nature06536.

3. Saunders-Hastings PR, Krewski D. Reviewing the history of pandemic influenza: understanding patterns of emergence and transmission. Pathogens 2016;5(4):66. http://dx.doi.org/10.3390/pathogens5040066.

4. Liu WJ, Wu Y, Bi YH, Shi WF, Wang DY, Shi Y, et al. Emerging HxNy influenza a viruses. Cold Spring Harb Perspect Med 2020; 14:a038406. http://dx.doi.org/10.1101/cshperspect.a038406.

5. Gao GF. From "A" IV to "Z" IKV: attacks from emerging and reemerging pathogens. Cell 2018;172(6):1157 - 9. http://dx.doi.org/10. 1016/j.cell.2018.02.025.

6. Daszak P, Olival KJ, Li HY. A strategy to prevent future epidemics similar to the 2019-nCoV outbreak. Biosaf Health 2020;2(1):6 - 8 . http://dx.doi.org/10.1016/j.bsheal.2020.01.003.

7. Shang ZF, Chan SY, Liu WJ, Li P, Huang W. Recent insights into emerging coronavirus: SARS-CoV-2. ACS Infect Dis 2021;7(6):1369 88. http://dx.doi.org/10.1021/acsinfecdis.0c00646.

8. Wang QH, Chen H, Shi Y, Hughes AC, Liu WJ, Jiang JK, et al. Tracing the origins of SARS-CoV-2: lessons learned from the past. Cell Res 2021;31(11):1139 - 41. http://dx.doi.org/10.1038/s41422-02100575-w.

9. Tan WJ, Zhao X, Ma XJ, Wang WL, Niu PH, Xu WB, et al. A novel coronavirus genome identified in a cluster of pneumonia cases - Wuhan, China 2019-2020. China CDC Wkly 2020;2(4):61 - 2. http://dx.doi. org/10.46234/ccdcw2020.017.

10. Munnink BBO, Worp N, Nieuwenhuijse DF, Sikkema RS, Haagmans B, Fouchier RAM, et al. The next phase of SARS-CoV-2 surveillance: real-time molecular epidemiology. Nat Med 2021;27(9):1518-24. http://dx.doi.org/10.1038/s41591-021-01472-w.

11. Song SH, Ma LN, Zou D, Tian DM, Li CP, Zhu JW, et al. The global landscape of SARS-CoV-2 genomes, variants, and haplotypes in 2019nCoVR. Genomics, Proteomics Bioinform 2020;18(6):749 - 59. http://dx.doi.org/10.1016/j.gpb.2020.09.001.

12. Han M, Gu JH, Gao GF, Liu WJ. China in action: national strategies to combat against emerging infectious diseases. Sci China Life Sci 2017;60(12):1383 - 5. http://dx.doi.org/10.1007/s11427-017-9141-3.

13. Liu WJ, Wu GZ. Convincing the confidence to conquer COVID-19: from epidemiological intervention to laboratory investigation. Biosaf Health 2020;2(4):185 - 6. http://dx.doi.org/10.1016/j.bsheal.2020.11. 005 .

14. Li ZJ, Liu FF, Cui JZ, Peng ZB, Chang ZR, Lai SJ, et al. Comprehensive large-scale nucleic acid-testing strategies support China's sustained containment of COVID-19. Nat Med 2021;27(5):740 - 2. http://dx.doi.org/10.1038/s41591-021-01308-7.

15. WHO. WHO-convened global study of origins of SARS-CoV-2: China Part. Joint WHO-China study: 14 January - 10 February 2021. https://www.who.int/publications/i/item/who-convened-global-studyof-origins-of-sars-cov-2-china-part. [2021-3-30].

16. Liu PP, Yang MJ, Zhao X, Guo YY, Wang L, Zhang J, et al. Cold-chain transportation in the frozen food industry may have caused a recurrence of COVID-19 cases in destination: successful isolation of SARS-CoV-2 virus from the imported frozen cod package surface. Biosaf Health 2020;2(4):199 - 201. http://dx.doi.org/10.1016/j.bsheal.2020.11.003.

17. Sakamoto $H$, Ishikane M, Ueda P. Seasonal influenza activity during the SARS-CoV-2 outbreak in Japan. JAMA 2020;323(19):1969 - 71 http://dx.doi.org/10.1001/jama.2020.6173.

18. Feng LZ, Zhang T, Wang Q, Xie YR, Peng ZB, Zheng JD, et al. Impact of COVID-19 outbreaks and interventions on influenza in China and the United States. Nat Commun 2021;12(1):3249. http:// dx.doi.org/10.1038/s41467-021-23440-1.

19. Soo RJJ, Chiew CJ, Ma S, Pung R, Lee V. Decreased influenza incidence under COVID-19 control measures, Singapore. Emerg Infect Dis 2020;26(8):1933 - 5. http://dx.doi.org/10.3201/eid2608.201229.

20. Cuadrado-Payán E, Montagud-Marrahi E, Torres-Elorza M, Bodro M, Blasco M, Poch E, et al. SARS-CoV-2 and influenza virus co-infection. Lancet 2020;395(10236):E84. http://dx.doi.org/10.1016/S0140-6736 (20)31052-7.

21. Xiang X, Wang ZH, Ye LL, He XL, Wei XS, Ma YL, et al. Co-infection 
of SARS-COV-2 and influenza a virus: a case series and fast review. Curr Med Sci 2021;41(1):51 - 7. http://dx.doi.org/10.1007/s11596021-2317-2.

22. Servick K. Coronavirus creates a flu season guessing game. Science 2020;369(6506):890 - 1. http://dx.doi.org/10.1126/science.369.6506. 890.

23. Liu JM, Zhang L, Yan YQ, Zhou YC, Yin P, Qi JL, et al. Excess mortality in Wuhan city and other parts of China during the three months of the covid-19 outbreak: findings from nationwide mortality registries. BMJ 2021;372:n415. http://dx.doi.org/10.1136/bmj.n415.

24. Gomez GB, Mahe C, Chaves SS. Uncertain effects of the pandemic on respiratory viruses. Science 2021;372(6546):1043 - 4. http://dx.doi. org/10.1126/science.abh3986.

25. Chotpitayasunondh T, Fischer TK, Heraud JM, Hurt AC, Monto AS, Osterhaus A, et al. Influenza and COVID-19: what does co-existence mean? Influenza Other Respir Viruses 2021;15(3):407 - 12. http://dx. doi.org/10.1111/irv.12824.

26. Zhang J, Lin H, Ye BW, Zhao M, Zhan JB, Dong SB, et al. One-year sustained cellular and humoral immunities of COVID-19 convalescents. Clin Infect Dis 2021ciab884. http://dx.doi.org/10.1093/ $\mathrm{cid} / \mathrm{ciab} 884$..

27. The Lancet. World Flu Day: momentum from China for influenza control. Lancet 2018;392(10158):1600. http://dx.doi.org/10.1016/ S0140-6736(18)32770-3.

28. Gao GF, Liu WJ. Let's get vaccinated for both flu and COVID-19: on the World Flu Day 2021. China CDC Wkly 2021;3(44):915 - 7. http: //dx.doi.org/10.46234/ccdcw2021.227.

29. Xiao CK, Xu JA, Lan Y, Huang ZP, Zhou LJ, Guo YX, et al. Five independent cases of human infection with avian influenza H5N6 Sichuan Province, China, 2021. China CDC Wkly 2021;3(36):751 6. http://dx.doi.org/10.46234/ccdcw2021.187. 